\section{THE SURGERY OF THE GOLON AND RECTUM}

By Sir-Hugh Devine, F.R.C.S., F.R.A.C.S., and JoHN Devine, F.R.C.S., F.R.A.C.S. Pp. 373. 277 illustrations. Bristol : John Wright \& Sons. 1948. 52s. $6 \mathrm{~d}$.

This eminently practical book comes from the Melbourne Medical School and the authors' names are an immediate guarantee of what lies within its covers. In some 350 pages the Devines cover the anatomy, physiology and surgery of the large intestine from ileo-caecal valve to anus. Sir Hugh's views on the defunctioned bowel and his method of performing colostomy are already well known in this country from his numerous papers on the subject, and his excellent book on the Surgery of the Alimentary Tract. His operating frame is also well known and probably lends itself better to the surgery of the large bowel than to other abdominal operations.

The book forms an excellent introduction for the younger surgeon since there is marked emphasis on practical details. The more experienced worker will derive no less benefit since the authors' own predilections are always presented and neat little case reports are interlarded to give point to the text. This is a book which all surgeons interested in the colon should read.

\section{S.F.T.}

\section{MAJOR ENDOCRINE DISORDERS}

By S. Leonard Simpson. 2nd Edition. Pp. 552. Oxford : Geoffrey Cumberlege, Medical Publications. I948. 42s.

Despite its title this is not a textbook of endocrinology. Rather is it composed of the author's personal views on a number of subjects. Within this limited sphere the book is in every way excellent, giving a clear picture of recent work in most of the main fields of endocrinology and in addition the author's own deductions. The references are full and include many to recent medical literature whilst the style of presentation is always clear and unencumbered by unnecessary words.

In a subject where personal opinions must still carry great weight, criticism of particular statements is of no value. This is an admirable introduction and guide to a difficult subject and represents remarkable value at the price.

$$
\text { S.F.T. }
$$

\section{THE MODERN MANAGEMENT OF GASTRIC} AND DUODENAL ULGER

Edited by F. Croxon Deller, M.D., M.R.C.P., D.A. Pp. 227. Edinburgh : E. \& S. Livingstone. 1948. 20 .

Readers of the Post Graduate Medical fournal will need no introduction to this book since it is a reprint of a series of articles previously published in the Journal. Brief notes on anatomy and physiology have been added and a thoughtful account of vagotomy.

The book is really beautifully published by Livingstone, who have excelled themselves in the quality of paper, illustrations and general format.

$$
\text { S.F.T. }
$$

\section{DISORDERS OF SEX AND REPRODUGTION}

By A. P. Pillay, O.B.E., M.B., B.S. Pp. xiv + 300 , with 2 plates. London: H. K. Lewis. I948. I8s.

The title of this book reveals its greatest fault. The sections on reproduction, in the narrow sense of fertility apart from sexuality, can only be described as poor, especially that on female fertility. The fact that these sections are only for general practitioners does not justify the omission of any reference to endometrial biopsy except that it is ' difficult,' nor the total neglect of cervical function. The hormone treatments would not be generally approved. To give only a few examples : progesterone is given in doses of $2 \mathrm{mgm}$. weekly for early abortion, the impression is given that testosterone will sometimes improve spermatogenesis, and apart from an indirect reference to gonadotropic hormone there is nothing in the text to show that the proper treatment of anovular cycles is understood. The vitamin $\mathrm{C}$ test for ovulation is not generally accepted, and the statement is made that abortions occur 'mostly on new and full moon days.' We were shocked to read that gynaecologists have 'occasion to remove a good many ovaries suitable for transplantation.'

This criticism is regretted as the 'sexual' sections are uniformly excellent. The factual statements of normal function and habit are fortified by case histories. The section on history taking would be useful to the inexperienced, who find this type of case both obscure and embarrassing. Psychiatrists may regret that their affairs are not given greater weight, but as the author remarks, the ordinary doctor can seldom do more than probe patiently into the past and present history of the sufferer, and make him realize the nature and causation of his malady, and that his condition is curable. The problems of venereal disease and pregnancy might be given more consideration.

We suggest that this book would be improved by omission of much of the 'endocrine' and 'reproductive' matter, which is so much better described elsewhere, but hope that further editions of the remainder will appear.

S.G.C.

\section{RECENT ADVANGES IN RESPIRATORY TUBERCULGSIS}

By Frederick Heaf, M.A., M.D., F.R.C.P., and N. LlOYD RUSBY, M.A., D.M., F.R.C.P. 4th Edition. Pp. vii +290 , with 5 plates and 7 text figures. London: J. \& A. Churchill. 1948. 2Is. 
Dr. Heaf and Dr. Rusby are to be congratulated on their presentation of this revised edition of the late Dr. Burrell's original contribution to the Recent Advances series. Such a revision was long overdue. It has been a task of considerable magnitude, involving the collection of a vast mass of new material and the selection from this of appropriate details, which had to be grafted on to Burrell's work in such a way as to maintain its essentially clinical character and at the same time to introduce much information in regard to aspects of the subject that belong mainly to the province of the statisticians and the public health authorities.

A salient feature of this volume and, in our view, one of its chief recommendations, is the success with which the authors have combined the purely clinical with the sociological and environmental features of pulmonary tuberculosis in a book which from beginning to end is characterized by balance and poise. It is this, no less than its intrinsic wealth of accurate and reliable information, which makes it, in our judgment, such excellent reading.

The first four chapters are conspicuous for their combination of conciseness with clarity. The account given of B.C.G. and the Vole Bacillus is particularly good. In Chapter V (Radiology) we feel there is room for some cons ructive criticism. Much has been devoted to technique and to mass radiography, but little to the routine interpretation of straight radiograms. We appreciate that the book is primarily concerned with recent advances, but the inclusion of a few more paragraphs on interpretation and the reproduction of some of Burrell's original blocks, illustrating typical phases of pulmonary disease, would surely have been justifiable (despite the title), and would have enhanced the value of the book for most students. Possibly the authors may be disposed to consider this point in future editions.

In Chapter VI (Complications), tuberculous enteritis and laryngitis are dealt with rather sparsely considering their frequency and importance, and here again we feel that the value of this chapter would have been increased by a few well chosen illustrations of the larynx.

The whole subject of the surgical treatment of tuberculosis has been well handled, and Chapters IX and $X$ should be especially valuable to a physician for chest disease who really intends, as he should, to see his patient as a whole and not to treat him, as so many do, by following the line of least resistance.

Chapter XI, on rehabilitation, is one of the best in the whole book. The authors have managed to compress into its 17 pages the essentials of a problem the full study of which must entail the perusal of many standard volumes and of endless official reports. The result is very readable and most informative. The same may be said of Chapter XII, on prognosis, one of the proverbial difficulties of the clinician. The information afforded by careful study of this chapter is considerable and forms as good a practical guide to the student as anything we have read on the subject.

Chapter XIV on the public health services gives $\stackrel{\mathbb{Q}}{\complement}$ an excellent account of the development of the $c$. present machinery, the working of which is clearly $\overrightarrow{\vec{*}}$ explained, the relations of the different units to $\stackrel{\vec{P}}{+}$ each other and to the whole being made clear by suitable diagrams.

This book is mainly for those engaged in tubercu- $\frac{\bar{\sigma}}{\bar{D}}$ losis work, but it can and should be read by the $\stackrel{\mathbb{Q}}{\Omega}$ senior undergiaduate and by the newly qualified $₫$ man and woman, whose opportunities for the study $\rightarrow$ of chest disease have diminished so much in the.

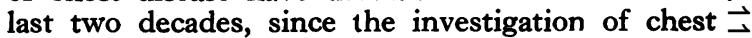
cases has departed more and more from the general $\omega$ hospital to special institutions. The volume is well documented and has an adequate and satisfactory index. It maintains the high standard characteristic of Messrs. Churchill's publications.

M.D.

\section{THE RH BLOOD GROUPS AND THEIR CLINIGAL EFFECTS}

Medical Research Council Memorandum No. I9 By P. L. Mollison, A. E. Mourant and R. R. 㞯 RACE. Pp. 74. London: His Majesty's Stationery Office. 1948. Is. 6d.

The discovery of the fact that human red blood corpuscles are agglutinated by anti-rhesus seruy. has led to the understanding of erythroblastosts and the haemolytic reactions which may follcw the administration of blood of compatible ABO groups. A great deal of literature has been published in this country and in America and this memorandum has done much to clarify the position as it stands in this country at the moment.

After a short historical introduction, the $\mathrm{Rh}$ blood groups are discussed by Race. The Fisher nomenclature is used throughout, but in certain tables the shorthand symbols are also given, some $\bar{x}$ of which were originally introduced by Wiener and $\underline{3}$. some by British workers. The initial paragraphs $\bar{\sigma}$ are of interest to clinicians generally, the subsequent review on the subject dealing with the genetic basis 8 of the Rh groups is primarily set out for laboratory workers.

The clinical considerations are clearly set out by Mollison and should be of interest to most clinicians, but especially to obstetricians, gynaecologists and paediatricians.

Finally Mourant deals with the problems of $\mathbb{O}$ laboratory testing of the blood.

This is an excellent memorandum and sets out 0 the present position of the $\mathrm{Rh}$ factor in a logical manner. It was initially marred by a few inaccuracies, but now that these have been corrected $\stackrel{\infty}{\rightarrow}$ this will undoubtedly prove a very valuable reference pamphlet to many.

S.M.N. 